\title{
A Novel Approach of Wireless Power Distribution
}

\author{
Ch. Jagan Mohan Rao ${ }^{1}$, Halini Samalla ${ }^{2}$, P. Vinayak ${ }^{3}$ \\ Assistant Professor, Department of EEE, Sri Sivani College of Engineering, Srikakulam, India ${ }^{1,2,3}$
}

\begin{abstract}
In the present paper the various technologies available so far for wireless transmission of electricity and the need for a Wireless System of Energy Transmission is being discussed to find its possibility in actual practices, their advantages, disadvantages and economical consideration. This paper is mainly concentrated on : i) The most popular concept known as Tesla Theory, ii) The microwave power transmission (MPT) called Solar power satellite, iii) The highly efficient fibre lasers for wireless power transmission and iv) a centralized solution for user interface. Many concepts, research papers, patents are available on wireless transmission of electricity but the commercial technologies are yet to be materialized. The paper also discusses the possible ways to get useful and practical results out of all research carried out so far elsewhere.
\end{abstract}

Keywords: Wireless transmission, Tesla theory, Microwave power transmission, Fiber lasers, Collaborative research.

\section{INTRODUCTION}

In our present electricity generation system we waste more than half of its resources. Especially the transmission and distribution losses are the main concern of the present power technology. Much of this power is wasted during transmission from power plant generators to the consumer. The resistance of the wire used in the electrical grid distribution system causes a loss of $26-30 \%$ of the energy generated. This loss implies that our present system of electrical distribution is only $70-74 \%$ efficient. We have to think of alternate state - of - art technology to transmit and distribute the electricity. Now- a- days global scenario has been changed a lot and there are tremendous development in every field. If we don't keep pace with the development of new power technology we have to face a decreasing trend in the development of power sector. The transmission of power without wires may be one noble alternative for electricity transmission.

In 1995 a small Public Utility District (PUD) on the West Coast of Washington State took a bold leap into the world of automation. Grays Harbor PUD installed a Programmable Logic Controller (PLC) based Supervisory Control and Data Acquisition (SCADA) to monitor and control their power distribution system. Normally only available to large utilities, this power control system links seven remote substations to a centralized facility over a 40 mile radius. This paper will give a technical overview of the control system and describe how a small power utility can benefit from innovative system design and an open PLC based control system. Grays Harbor PUD is headquartered in Aberdeen, Washington on the North side of Grays Harbor (Figure 1). Grays Harbor PUD receives power from Bonneville Power Supply's transmission grid and distributes it to a population of 67,000 (1996 survey) over 1,800 square miles. The highly wooded areas and coastal terrain made designing a reliable SCADA system very challenging. A SCADA system allows remote operation of substation equipment, including full circuit breaker control, power system alarming, real-time power flow indication, and logging of system conditions.
The implementation of a SCADA system for power distribution is usually reserved for larger power utilities. The systems are generally custom designed for a utility company and have proprietary equipment that is very costly to implement and maintain. Grays Harbor PUD's approach to system design integrated an "off the shelf" PLC network. PLCs have been the backbone of industrial control since the early 1970s. There is an established distribution network for PLCs and local technical support in most areas. A PLC based network provides an open system design on a standardized platform at a muchreduced hardware and maintenance cost. The open system makes changes easy and additional sites can be integrated with minimal impact on the network.

\section{THE TECHNOLOGIES AVAILABLE}

In this remarkable discovery of the "True Wireless" and the principles upon which transmission and reception, even in the present day systems, are based, Dr. Nikola Tesla shows us that he is indeed the "Father of the Wireless." The most well known and famous Wardenclyffe Tower (Tesla Tower) was designed and constructed mainly for wireless transmission of electrical power, rather than telegraphy [1]. The most popular concept known is Tesla Theory in which it was firmly believed that Wardenclyffe would permit wireless transmission and reception across large distances with negligible losses [2]. In spite of this he had made numerous experiments of high quality to validate his claim of possibility of wireless transmission of electricity. But this was an unfortunate incidence that people of that century was not in a position to recognize his splendid work otherwise today we may transmit electricity wirelessly and will convert our mother earth a wonderful adobe full of electricity.

The modern ideas are dominated by microwave power transmission (MPT, Figure 1) called Solar power satellite to be built in high earth orbit to collect sunlight and convert that energy into microwaves, then beamed to a 
very large antenna on earth, the microwaves would be converted into conventional electrical power.

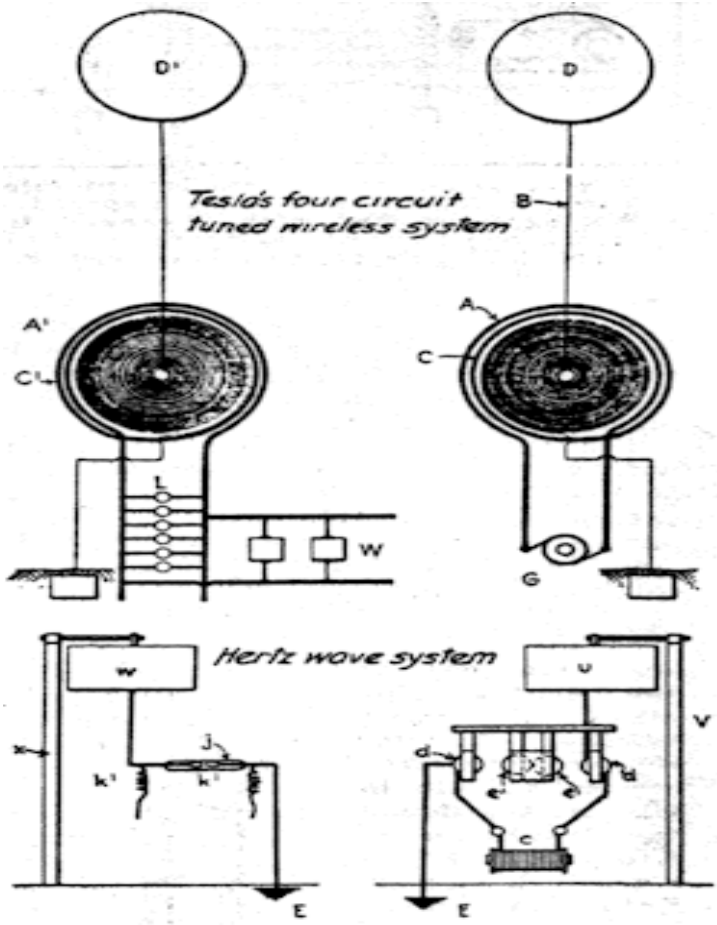

Fig.1: The basis for Tesla's system for the wireless transmission of electrical power

William C. Brown, the leading authority on wireless power transmission technology, has loaned this demonstration unit to the Texas Space Grant Consortium to show how power can be transferred through free space by microwaves. A block diagram of the demonstration components is shown below. The primary components include a microwave source, a transmitting antenna, and a receiving rectenna the microwave source consists of a microwave oven magnetron with electronics to control the output power. The output microwave power ranges from $50 \mathrm{~W}$ to $200 \mathrm{~W}$ at $2.45 \mathrm{GHz}$. A coaxial cable connects the output of the microwave source to a coax-to-waveguide adapter. This adapter is connected to a waveguide ferrite circulator which protects the microwave source from reflected power. The circulator is connected to a tuning waveguide section to match the waveguide impedance to the antenna input impedance.

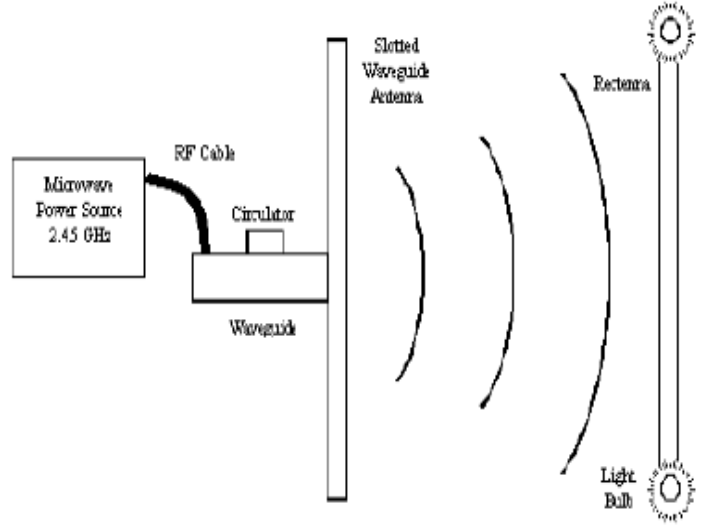

Fig. 2: Microwave power transmission
The slotted waveguide antenna consists of 8 waveguide sections with 8 slots on each section. These 64 slots radiate the power uniformly through free space to the rectenna. The slotted waveguide antenna is ideal for power transmission because of its high aperture efficiency (> 95\%) and high power handling capability.

A rectifying antenna called a rectenna receives the transmitted power and converts the microwave power to direct current (DC) power. This demonstration rectenna consists of 6 rows of dipoles antennas where 8 dipoles belong to each row. Each row is connected to a rectifying circuit which consists of low pass filters and a rectifier. The rectifier is a $\mathrm{Ga}$ as Schottky barrier diode that is impedance matched to the dipoles by a low pass filter. The 6 rectifying diodes are connected to light bulbs for indicating that the power is received. The light bulbs also dissipated the received power. This rectenna has a $25 \%$ collection and conversion efficiency, but rectennas have been tested with greater than $90 \%$ efficiency at 2.45 $\mathrm{GHz}[4]$. The transmission of power without wires is not a theory or a mere possibility, it is now a reality. The electrical energy can be economically transmitted without wires to any terrestrial distance, many researchers have established in numerous observations, experiments and measurements, qualitative and quantitative [5-9]. These have demonstrated that it is practicable to distribute power from a central plant in unlimited amounts, with a loss not exceeding a small fraction of one per cent, in the transmission, even to the greatest distance, twelve thousand miles - to the opposite end of the

globe. This seemingly impossible feat can now be readily performed by electrical researchers familiar with the design and construction of my "high-potential magnifying transmitter," There were three popular theories present in the literature of the late 1800's and early 1900's. They were:

1. Transmission through or along the Earth,

2. Propagation as a result of terrestrial resonances,

3. Coupling to the ionosphere using propagation through Electrified gases.

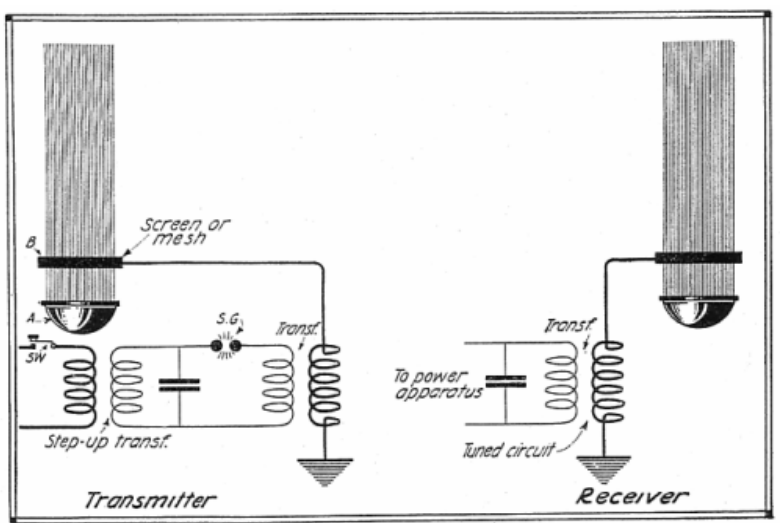

Fig .3: Diagram showing the transmitting \& receiving circuit for the transmission \& reception of electric power by wireless

It has been proven that electrical energy can be propagated around the world between the surface of the Earth and the ionosphere at extreme low frequencies in what is known as the Schumann Cavity. 


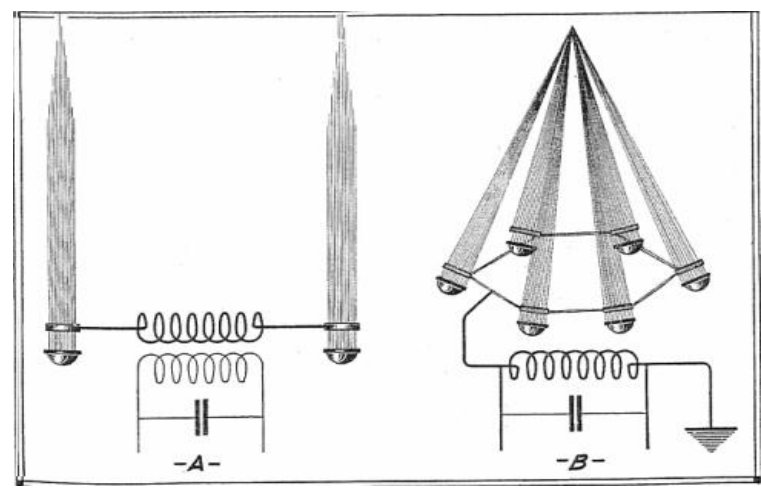

Fig. 4: Two optical forms of wireless antennae formed of search light beam- ionised atmospheric streams

Knowing that a resonant cavity can be excited and that power can be delivered to that cavity similar to the methods used in microwave ovens for home use, it should be possible to resonate and deliver power via the Schumann Cavity to any point on Earth. This will result in practical wireless transmission of electrical power.

Although Tesla was not able to commercially market a system to transmit power around the globe, modern scientific theory and mathematical calculations support his contention that the wireless propagation of electrical power is possible and a feasible alternative to the extensive and costly grid of electrical transmission lines used today for electrical power distribution.

Power transmission system using directional ultrasound for power transmission includes a transmitting device and a receiving device. The transmitting device has a set of ultrasound transducers forming an ultrasound transducer array, wherein the array is a set of spaced individual transducers placed in the $\mathrm{X}-\mathrm{Y}$ plane disposed to generate an ultrasound beam in the $\mathrm{Z}$ direction [6]. Another possibility is to use highly efficient fibre lasers for wireless power transmission where the possibilities are similar to microwaves concept but lasers emit energy at frequencies much higher that microwaves.

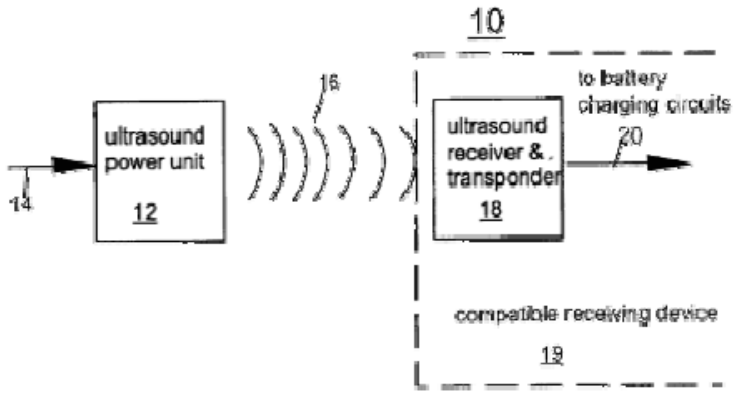

Fig. 5: System and method for wireless electrical power Transmission

\section{III.MERITS DEMERITS AND ECONOMICS OF WIRELESS TECHNOLOGIES}

An electrical distribution system, based on this method would eliminate the need for an inefficient, costly, and capital intensive grid of cables, towers, and substations. The system would reduce the cost of electrical energy used by the consumer and rid the landscape of wires, cables, and transmission towers.
There are areas of the world where the need for electrical power exists, yet there is no method for delivering power. Africa is in need of power to run pumps to tap into the vast resources of water under the Sahara Desert. Rural areas, such as those in China, require the electrical power necessary to bring them into the 20th century and to equal standing with western nations. The wireless transmission will solve many of these problems The electrical energy can be economically transmitted without wires to any terrestrial distance, so there will be no transmission and distribution loss.

More efficient energy distribution systems and sources are needed by both developed and under developed nations. In regards to the new systems, the market for wireless power transmission is enormous. It has the potential to become a multi-billion dollar per year market. The increasing demand for electrical energy i $\mathrm{n}$ industrial nations is well documented. If we include the demand of third world nations, pushed by their increasing rate of growth, we could expect an even Faster rise in the demand for electrical power in the near future. These systems can only meet these requirements with 90-94 \%efficient transmission $[3,8]$.

High Transmission Integrity and Low Loss: - To transmit wireless power to any distance without limit. It makes no difference what the distance is. The efficiency of the transmission can be as high as 96 or 97 per cent, and there are practically no losses.

Biological Impact: - One common criticism of the Tesla wireless power system is regarding its possible biological effects. Calculating the circulating reactive power, it was found that the frequency is very small and such a frequency is very biologically compatible $[3,8]$.

The concept looks to be costly initially. The investment cost of Tesla Tower was $\$ 150,000$ (1905). In terms of economic theory, many countries will benefit from this service. Only private, dispersed receiving stations will 1 be needed. Just like television and radio, a single resonant energy receiver is required, which may eventually be built into appliances, so no power cord will be necessary! Monthly electric utility bills from old-fashioned, fossilfuelled, loss prone electrified wire-grid delivery services will be optional, much like "cable TV" of today. In the 21 st century, "Direct TV" is the rage, which is an exact parallel of Tesla's "Direct Electricity."

\section{IV.CENTRALIZED POWER DISTRIBUTION}

Reliable communication is critical to any SCADA system. Two of the remote substation sites had existing microwave radios and one could be connected on the local area network. For the five remaining locations the Grays Harbor PUD reviewed several communication options before selecting the ESTeem Wireless Modem system. The commercial telephone leased line option was ruled out because of cost, substation ground isolation problems, and reliability. Various radio systems were tested at higher frequencies and were unsuccessful due to the difficult terrain and the long distances involved. The ESTeem Model 96C, operating in a frequency band of 450-470 $\mathrm{MHz}$, was tested and found to be reliable in their application. The esteem Wireless Modems have an 
integral Allen-Bradley protocol driver built into every unit. The protocol driver allowed quick integration with the selected Allen-Bradley PLC and with the addition of external linear amplifiers at the main and repeater sites, a reliable 30-mile radio link was established. Another 450$470 \mathrm{MHz}$ radio network is planned which will allow SCADA system perators to control ten transmission switches.

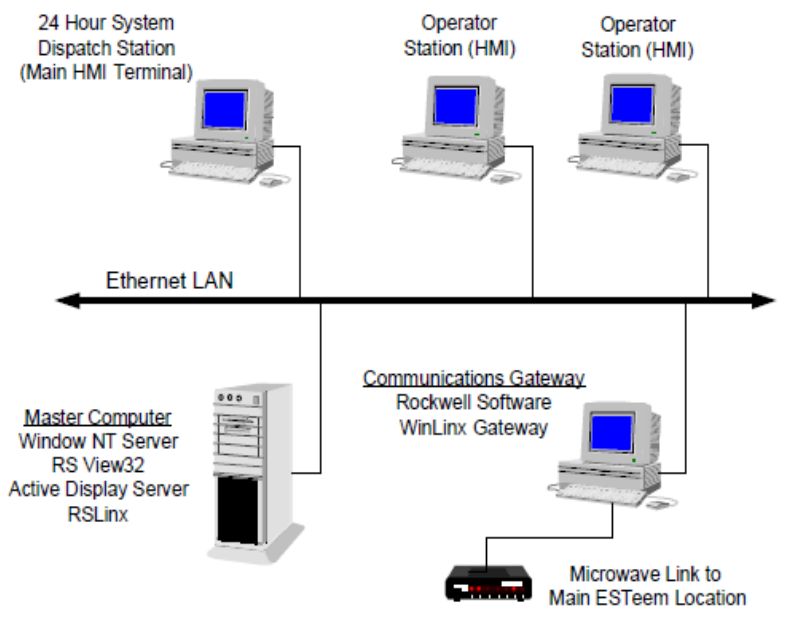

Fig. 6: Main Office Computer System

The Grays Harbor PUD Main Office is located in Aberdeen, Washington and is the center point for the SCADA system. At the main office is the communications gateway, master computer and operator stations (Figure 2). An Ethernet LAN is used to connect the Windows NT computers to complete the system. The communications gateway computer uses Rockwell Automation's Winlinx gateway to pass through data requests between the DF1 connected substations and the Ethernet computers. The master computer uses Rockwell Automation's RSView32 and Active Display Server to act as a central data concentrator and control hub. RSView32 Active Display Client software is used on multiple operator stations the Human Machine Interface (HMI)

The operator stations allow the 24-hour dispatching operation to monitor and control the power system. Other operator stations configured with less security may view the operation of the power system. Another application of the SCADA system is to gather and report energy usage information for the power purchase managers. The centralized communications gateway computer uses a microwave radio connection to a hilltop radio site where the ESTeem radio equipment is located. This allows the ESTeem to cover the distances and terrain of the area (Figure 3)

A dedicated microwave channel is set up for 4800 Baud to be used for the ESTeem radio network. The hill top ESTeem serves as the master radio with the substation ESTeem serving as the slaves (Figure 4). The SCADA master computer polls for information as required and regularly checks for alarm conditions. The SCADA master gathers information in a number of different ways. Alarm conditions are hecked as frequently as possible and control commands are issued immediately.

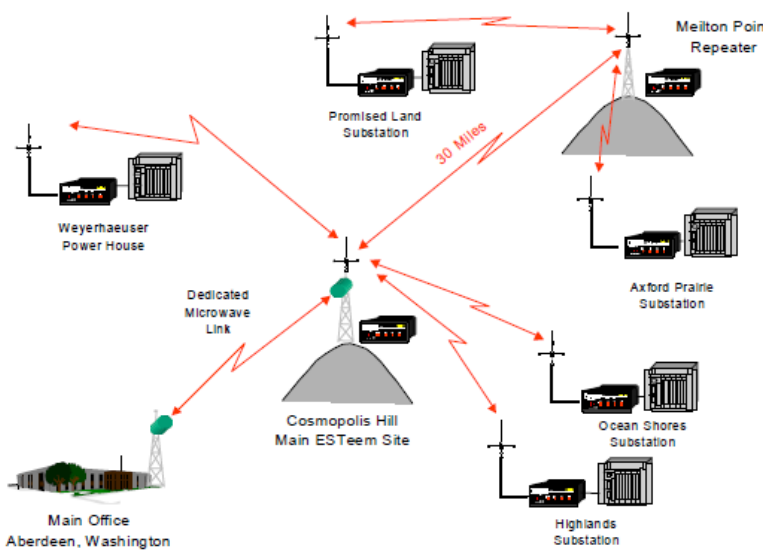

Fig .7: Site Layout Diagram

The centralized communications gateway computer uses a microwave radio connection to a hilltop radio site where the ESTeem radio equipment is located. This allows the ESTeem to cover the distances and terrain of the area (Fig. 7). A dedicated microwave channel is set up for 4800 Baud to be used for the ESTeem radio network. The hill top ESTeem serves as the master radio with the substation ESTeem serving as the slaves (Figure 4).

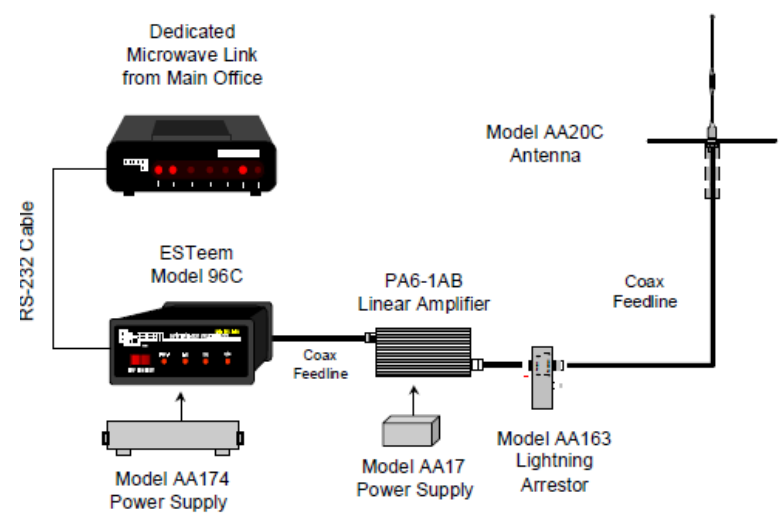

Fig.8: Main ESTeem Site Layout

The SCADA master computer polls for information as required and regularly checks for alarm conditions. The SCADA master gathers information in a number of different ways. Alarm conditions are checked as frequently as possible and control commands are issued immediately. Some information is only gathered when an operator requests it and some information is gathered only when an hourly report needs to be made. Other pieces of information are gathered at regular intervals for monitoring purposes. Each of the remote substations has a similar hardware configuration.

The Allen-Bradley PLC $5 / 20$ is used for the substation Remote Terminal Unit (RTU) to automate local functions, concentrate data, and pass data through from the substation equipment to the master computer. An ESTeem Model 96C is connected directly to the RS-232 port on the PLC 5/20 (Port 0). No additional hardware is required. Some of the remote locations require directional antennas where others use only whip antennas. Two of the remote radios communicate through a $2000-\mathrm{ft}$ high repeater located 30 miles north of the main hill top radio. 
INTERNATIONAL JOURNAL OF INNOVATIVE RESEARCH IN ELECTRICAL, ELECTRONICS, INSTRUMENTATION AND CONTROL ENGINEERING Vol. 3, Issue 10, October 2015

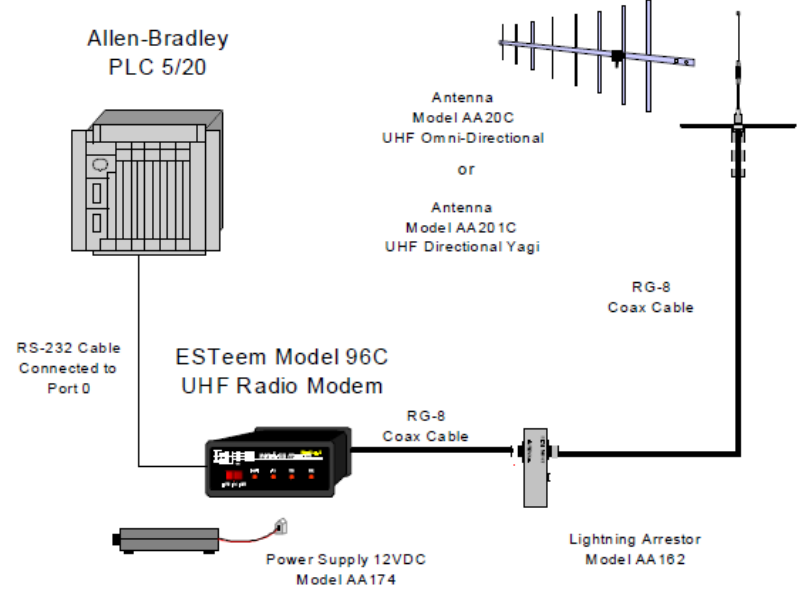

Fig.9: Remote Substation Equipment Layout

\section{CONCLUSION}

In The transmission of power without wires is not a theory or a mere possibility, it is now a reality. The electrical energy can be economically transmitted without wires to any terrestrial distance. Many researchers have established in numerous observations, experiments and measurements, qualitative and quantitative. Dr. N. Tesla is the pioneer of this invention. Wireless transmission of electricity have tremendous merits like high transmission integrity and Low Loss (90 - $97 \%$ efficient) and can be transmitted to anywhere in the globe and eliminate the need for an inefficient, costly, and capital intensive grid of cables, towers, and substations. The system would reduce the cost of electrical energy used by the consumer and get rid of the landscape of wires, cables, and transmission towers. It has negligible demerits like reactive power which was found insignificant and biologically compatible. It has a tremendous economic impact to human society. Many countries will benefit from this service. Monthly electric utility bills from old-fashioned, fossil-fuelled, loss prone electrified wire-grid delivery services will be optional, much like "cable TV" of today. From the above description we proposed a centralized method for operate from user side. Our future task is to establish high power transmission.

\section{REFERENCES}

[1] Nikola Tesla, "The Transmission of Electrical Energy Without Wires as a Means for Furthering Peace," Electrical World and Engineer. Jan. 7, p. 21, 1905.

[2] Nikola Tesla, My Inventions, Ben Johnston, Ed., Austin, Hart Brothers, p. 91, 1982.

[3] Thomas F. Valone, "Tesla's Wireless Energy... For the 21st Century!!! One Step beyond Direct TV!!!” Extra Ordinary Technology, 1, no. 4, Oct / Nov / Dec 2003.

[4] James O. McSpadden, "Wireless Power Transmission Demonstration", Texas A\&M University, June, 1997.

[5] Thomas W. Benson, "Wireless transmission of power now possible", News Letter, pp1118 - 9, March, 1920.

[6] Charych Arthur (Setauket, NY), "System and method for wireless electrical power transmission", Patent No. 6,798,716, September 28, 2004.

[7] Joe T. Howell, ET. al, "Advanced receiver / converter experiments for laser wireless power transmission" 5 th. Wireless transmission conference, pp 1-8, Garanda, Spain, 2004.
[8] Nikola Tesla, "The true wireless", Electrical Experiments, May, 1919.

[9] Toby Grotz," Wireless transmission of power", Courtesy of the Tesla BBS at 719 486-2775, August 28, 1990 